\title{
Gaitán: imágenes, monumento y memoria
}

\section{Carlos A. Flórez López}

Recibido: 8 de agosto de 2017

Enviado a pares evaluadores: 15 de agosto de 2017

Aprobado por pares evaluadores: 12 de septiembre de 2017

Aprobado por Comité Editorial: 22 de septiembre de 2017 DOI: 10.22395/csye.v6n12a8

\section{RESUMEN}

$\mathrm{El}$ objeto de este ensayo es reflexionar sobre la imagen de Jorge Eliécer Gaitán en la construcción de memoria e identidades colectivas en la sociedad colombiana, teniendo como eje central de la discusión las formas de representación política del líder liberal y sus implicaciones en la construcción de imágenes, monumentos y homenajes simbólicos que recuerdan sus ideas y formas de hacer política. Se trata de establecer un debate sobre los lugares de memoria de líderes políticos que posee la sociedad colombiana, en particular, se indaga sobre la relación que tiene los monumentos históricos con la imagen valorativa del caudillo liberal Jorge Eliecer Gaitán.

Palabras clave: imaginarios, memoria, símbolos, cultura política, mito político.

Doctor en Historia e historiador. Profesor de la Facultad de Ciencias Sociales del Colegio Mayor de Antioquia. Correo electrónico: carlos.florez@colmayor.edu.co 


\section{Gaitán: images, monument and memories}

\section{ABSTRACT}

The object of this essay is to think over Jorge Eliécer Gaitán's image in the construction of memory and collective identities in Colombian society, having as central discussion axis, political representation ways of the liberal leader and his involvement in the construction of images, monuments and symbolic tributes that remind people his ideas and ways to make politics. The

idea is to create a debate upon memory places of political leaders that Colombian society has, particularly, it enquires about the relationship that historical monuments have with the image of the liberal leader Jorge Eliécer Gaitán.

Keywords: imaginary; memories; symbols; political culture; political myth.

\section{Gaitan: imagens, monumento e memória}

\section{RESUMO}

O objetivo deste ensaio é refletir sobre a imagem de Jorge Eliécer Gaitán na construção de memória e identidades coletivas na sociedade colombiana, considerando como eixo central da discussão as formas de representação política do líder liberal e suas consequências na construção de imagens, monumentos e homenagens simbólicas que fazem lembrar suas ideias

e formas de fazer política. Trata-se de estabelecer um debate sobre os lugares de memória de líderes políticos que a sociedade colombiana possui; em particular, questiona-se sobre a relação que os monumentos históricos têm com a imagem valorativa desse líder.

Palavras-chave: cultura política; imaginários; memória; mito político; símbolos. 


\section{Introducción}

El lugar de Jorge Eliécer Gaitán en la sociedad colombiana ha estado determinado por la magnitud de su muerte y las implicaciones posteriores a la misma. Su vida ha sido estudiada desde la historiografía política ${ }^{1}$ y desde los estudiosos de la violencia que han dejado un importante acervo documental que invita a la reflexión y análisis sobre las ideas, proyectos y propuestas que marcaron los escenarios de la política desde la década de los años veinte del siglo XX hasta el presente.

Antes y después de su asesinato la imagen del caudillo se manifiesta en la apropiación de sus seguidores y militantes en torno a un fervor político, una pasión que produce un seguimiento fiel a sus ideas y a la imagen combativa que transmitía en sus discursos, posturas y acciones. La evocación de Gaitán despierta dos paradojas: "La primera: su importancia histórica no resulta solo de su obra política sino aún más de lo que no pudo realizar (...). La segunda: todo retrato de Gaitán inicia con su muerte" (Tahar, 2009, p. 251). Por ello, posterior a su asesinato se han realizado sendos homenajes en monumentos, placas, bustos y demás objetos de memoria que buscan perpetuar su legado a lo largo y ancho de la geografía colombiana en ciertos lugares adecuados para tal fin.

Estos escenarios, ámbitos o espacios físicos que evocan la imagen de Gaitán bien pueden acercarse a la noción de lugares de memoria que nos plantea Pierre Nora:

Los lugares de memoria son, en primer lugar, restos. La forma externa donde subsiste una consciencia conmemorativa en una historia que la convoca porque la ignora. La desritualización de nuestro mundo es la que hace aparecer la noción. Lo que segrega, erige y establece, construye, decreta, mantiene por el artificio y por la voluntad una colectividad fundamentalmente entrenada en su transformación y renovación (Nora, 2009, p. 24).

La figura de Gaitán y de otros "mártires" políticos se inscribe en esta noción, porque son "restos" de una imagen valorativa del recuerdo de un líder político, que rememora su muerte a través de una estatua o un busto conmemorativo. De allí, la intencionalidad de cada uno de estos lugares, y el objetivo de la creación de estos monumentos de memoria, que según Nora

[...] nacen y viven del sentimiento de que no hay memoria espontánea, que hay que crear archivos, que hay que mantener los aniversarios, organizar celebraciones, pronunciar elogios fúnebres, levantar actas, porque estas operaciones no son naturales (Nora, 2009, p. 24).

1 Véase por ejemplo los trabajos de Herberr Braun, Mataron a Gaitán, Bogotá, Norma, 1998. John, Green. Gaitanismo, liberalismo y movilización popular, Medellín, Fondo Editorial Eafit, 2013, Darío Acevedo Carmona. Política y caudillos colombianos en la caricatura editorial. 1920-1950, Medellín, La Carreta. 2009 y Adriana Rodríguez Franco, El gaitanismo y los gaitanistas de Jornada, tesis de Maestría en Historia, Universidad Nacional de Colombia, Bogotá, 2012. 
Desde luego, estos lugares no son naturales, responden a la necesidad de la sociedad y sectores partidistas por recordar y mitificar una idea, un sentimiento, una nostalgia por un pasado glorioso o doloroso que no volverá, pues se necesita cuidar un legado y conservar un proyecto político para perpetuarlo en el tiempo, como guardianes del pasado, puesto que:

Sin vigilancia conmemorativa, la historia los barrería rápidamente. Son los bastiones sobre los cuales se sostienen. Pero si lo que defienden no estuviera amenazado no habría necesidad de construirlos. Si viviéramos realmente los recuerdos que ellos encierran, serían inútiles. Si, por el contrario, la historia no se adueñara de ellos para deformarlos, transformarlos, y petrificarlos, no serían lugares para la memoria (Nora, 2009, p. 24).

En tal sentido, los monumentos y artefactos conmemorativos se convierten en documentos para comprender el uso de la imagen y la reinvención de la misma en el presente. Teniendo en cuenta a Le Goff el documento "no es una mercancía estancada del pasado, es un producto de la sociedad que lo ha fabricado" (Le Goff, 1991. p. 236).

En esta construcción o artilugio, intervienen sectores como el Estado, la sociedad o grupos de personas, -en ocasiones los tres sectores en simultáneomotivados a elaborar unos lugares de memoria que se convierten en documentos para el análisis social e histórico, pues son "el resultado del esfuerzo cumplido por las sociedades históricas por imponer el futuro -queriéndolo o no queriéndolo- aquella imagen dada de sí mismas" (Le Goff, 1991. p. 238).

Según lo anterior, surge un interrogante: ¿cuál es la imagen que se ha querido y se quiere mantener de Jorge Eliécer Gaitán? Pues bien, en esta reflexión se abordarán algunos elementos clave para responder a esta inquietud. Para ello, se tendrán como marco de referencia imágenes, afiches, lugares de memoria como monumentos, estatuas, bustos, objetos conmemorativos y caricaturas.

\section{Imágenes}

La imagen es un documento histórico que permite vislumbrar percepciones y creencias de una época y posibilita construir un cuadro valorativo de las ideas que marcaron una sociedad, un acontecimiento o un proyecto político. Como sostiene Peter Burke: "las imágenes nos permiten -imaginar- el pasado de un modo más vivo (...) Aunque los textos también nos ofrecen importantes pistas, las imágenes son la mejor guía para entender el poder que tenían las representaciones visuales en la vida política y religiosa de las culturas pretéritas" (Burke, 2001, p. 17) Analicemos algunos ejemplos de las imágenes de mayor recordación de Jorge Eliécer Gaitán: 
Afiches. En su campaña presidencial, los afiches de la época dan cuenta de dicha euforia y exaltación por los valores que defendía el líder del liberalismo. Observemos el siguiente afiche:

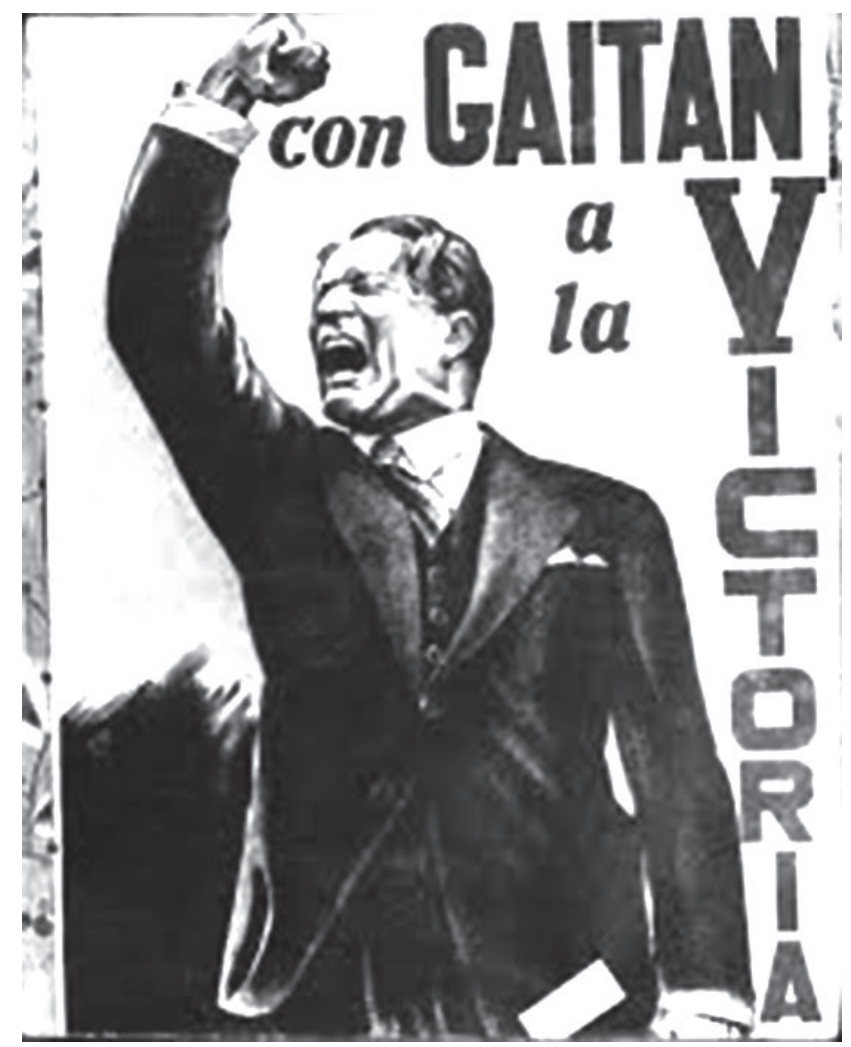

Afiche campaña presidencial

Fuente: Casa Museo Jorge Eliécer Gaitán https://www.flickr.com/photos/casaGaitán/3856901923/in/ photostream/

En esta imagen se aprecian el vigor y la fuerza que promovía el caudillo, con el afán de mantener cautivos a sus seguidores. Su mano derecha en puño cerrado en señal de combate promueve la idea de estar a la expectativa, de estar atentos a la lucha por conseguir los objetivos políticos. El texto que acompaña el afiche deja claro el nivel de caudillismo ejercido por el líder. Es Gaitán quien puede conseguir el poder asumido como grito de victoria, tal como un campo de batalla cuando un ejército logra ganar la guerra.

Lugar de su muerte. Está situado en la carrera séptima de la ciudad de Bogotá, lugar donde fue asesinado el 9 de abril de 1948. En el sitio hay una serie de placas conmemorativas, que recuerdan la memoria del líder; veamos la fotografía del lugar: 


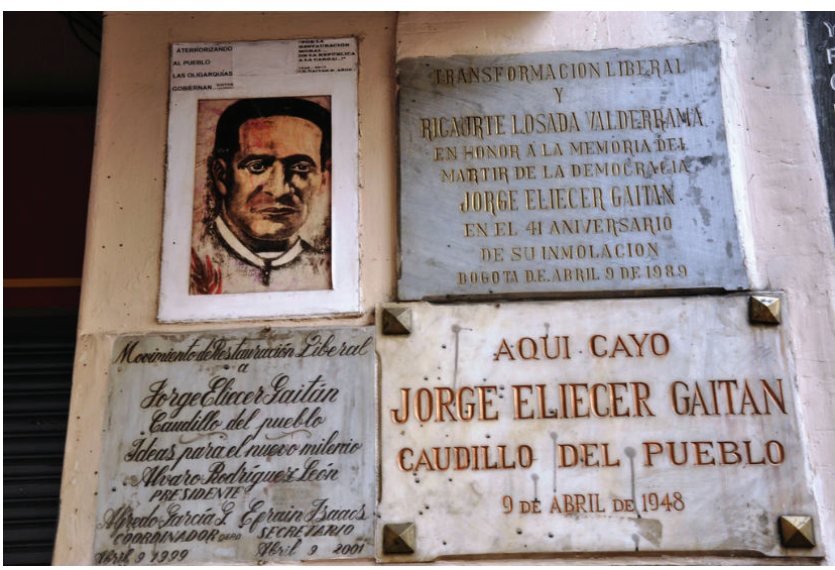

Lugar donde fue asentando Jorge Eliécer Gaitán

Fuente: https://www.flickr.com/photos/pat_ossa/6303251564

Al examinar los textos de las placas conmemorativas que residen en el lugar se pueden analizar las siguientes ideas-fuerza que permiten inferir los contenidos temáticos de dicho lugar de memoria

Cuadro No. 1. Percepciones de memoria

\begin{tabular}{|l|l|}
\hline \multicolumn{1}{|c|}{$\begin{array}{c}\text { Placas } \\
\text { conmemorativas }\end{array}$} & \multicolumn{1}{c|}{ Ideas-fuerza } \\
\hline $\begin{array}{l}\text { Paladín de la demo- } \\
\text { cracia }\end{array}$ & $\begin{array}{l}\text { Hace alusión a la lucha permanente de Gaitán por alcanzar el poder } \\
\text { por la vía democrática y la defensa de los derechos en el marco de } \\
\text { la democracia. }\end{array}$ \\
\hline Luchador popular & $\begin{array}{l}\text { Es conocido el fervor que tienen los gaitanistas por la imagen de } \\
\text { luchador político de su líder que agitaba la defensa de los derechos } \\
\text { del "pueblo". }\end{array}$ \\
\hline $\begin{array}{l}\text { Corazón de los } \\
\text { hombres libres de }\end{array}$ & $\begin{array}{l}\text { Esta frase destaca el espíritu libertario que promovía Gaitán y lo } \\
\text { catapulta como líder no solo de Colombia, sino de todo el continente } \\
\text { americano. }\end{array}$ \\
\hline Caudillo del pueblo & $\begin{array}{l}\text { Una de las formas de hacer política en Colombia se fundamenta en } \\
\text { el caudillismo. Esta denominación "caudillo del pueblo" sintetiza } \\
\text { el lugar de memoria que tiene Gaitán en el imaginario político en } \\
\text { la sociedad colombiana. }\end{array}$ \\
\hline $\begin{array}{l}\text { Ideas para el nuevo } \\
\text { milenio }\end{array}$ & $\begin{array}{l}\text { Las ideas de Gaitán han sido objeto de estudio y reflexión y han } \\
\text { sido retomadas para diversos proyectos políticos. }\end{array}$ \\
\hline $\begin{array}{l}\text { Discurso con la } \\
\text { firma de Gaitán }\end{array}$ & $\begin{array}{l}\text { El fragmento de unos de los discursos firmados por el mismo Gaitán } \\
\text { alimenta la idea del mito político y el lugar de memoria predilecto } \\
\text { para recordar sus ideas. }\end{array}$ \\
\hline
\end{tabular}


El billete de mil pesos. El billete es emitido por el Banco de la Republica en el año 2001; se destaca en su anverso la imagen de Jorge Eliécer Gaitán en una actitud serena y sosegada, tal como se aprecia a continuación:

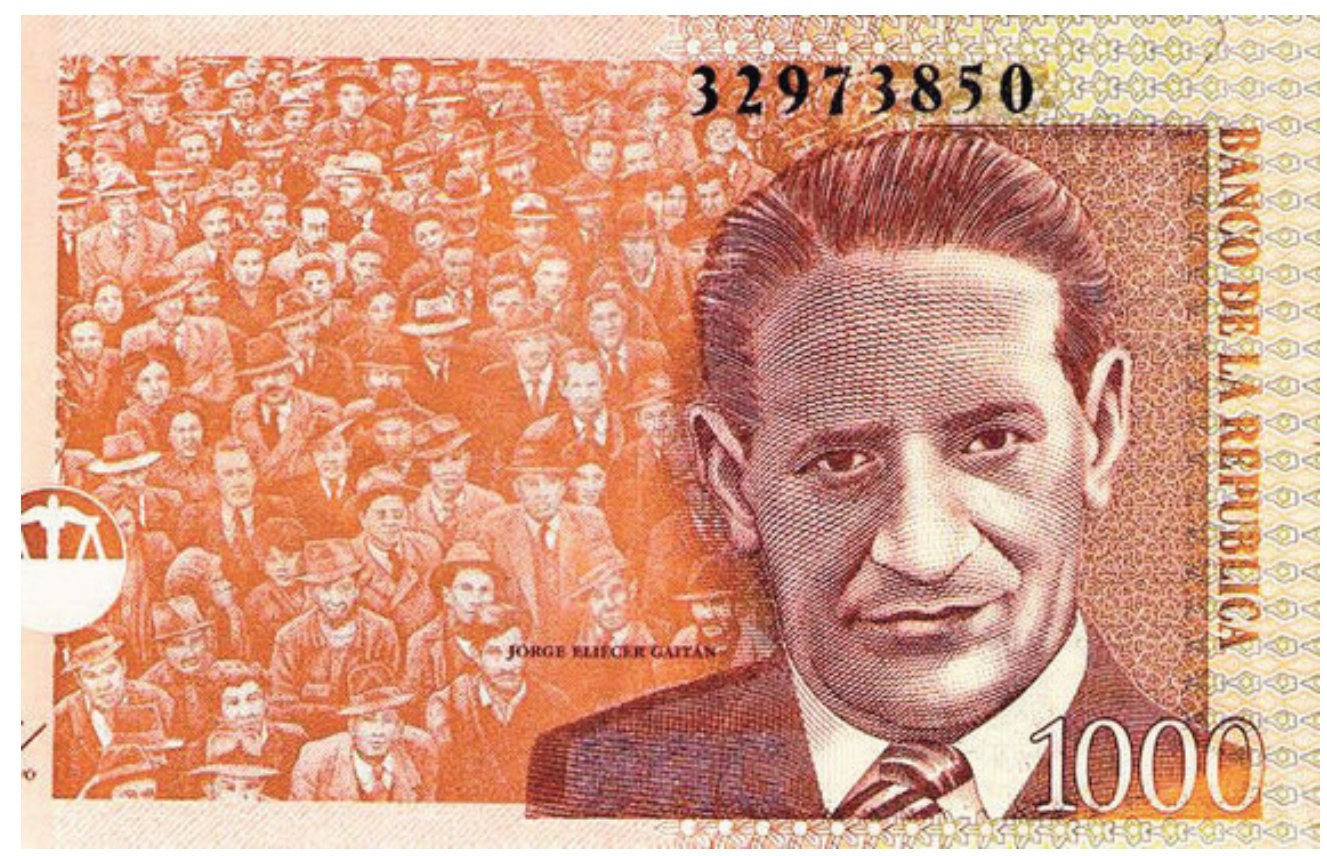

Fragmento anverso billete mil pesos colombianos

Fuente: http://www.banrep.gov.co/es/billetes-y-monedas/billete-1000-pesos

Detrás de su cara, las masas que seguían sus ideas están expectantes para escuchar sus discursos. Al lado izquierdo del billete está una balanza que representa la actividad laboral de Gaitán, abogado especializado en asuntos penales. Es llamativo el color naranja del billete con el objeto de apartarlo del color de sus ideas que empezaron con la $\mathrm{UNIR}^{2}$ que defendía el rojo y el negro y terminaron en el liberalismo donde solo se destaca el rojo.

En el reverso, se ilustra al líder saludando a las masas con su mirada en lontananza y rostro esperanzador, veamos la imagen:

2 La Unión Nacional de Izquierda revolucionaria UNIR fue un partido político de izquierda conformado por Jorge Eliécer Gaitán, en los años treinta del siglo XX. Para comprender la Unir véase los siguientes textos: César A. Ayala Diago, "La Unir entre Gaitan y los gaitanistas". La división creadora: influjo de las disidencias en el liberalismo colombiano. Rodrigo Llano Isaza, Bogotá, Academia Liberal de Historia, 2005, pp. $124-140$ y Carlos A. Flórez López, "La Unión Nacional de Izquierda Revolucionaria. Rojo y Negro", Derecha e izquierda en Colombia. 1920-1936. Estudio de los imaginarios políticos, Medellín, Universidad de Medellín, 2010, pp. 312-326. 


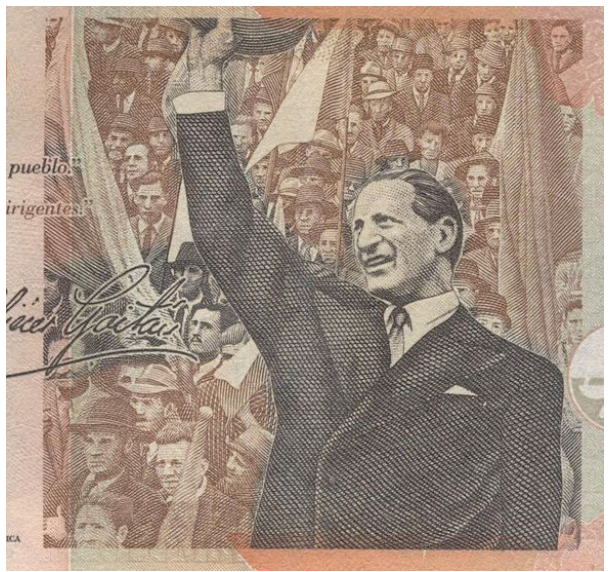

Fragmento reverso billete mil pesos colombianos

Fuente: http://www.banrep.gov.co/es/billetes-y-monedas/billete-1000-pesos

De nuevo las masas atrás ondeando banderas de Colombia y banderas rojas del partido liberal. La imagen la acompañan dos frases célebres usadas por el caudillo: "yo no soy un hombre, soy un pueblo" y "el pueblo es superior a sus dirigentes" al igual que una réplica de su firma.

No obstante, el billete ha sido objeto de intervenciones por quienes quieren mofarse del icono político que representa Gaitán. Analicemos algunos ejemplos:

\section{Billete con imagen de mendigo}

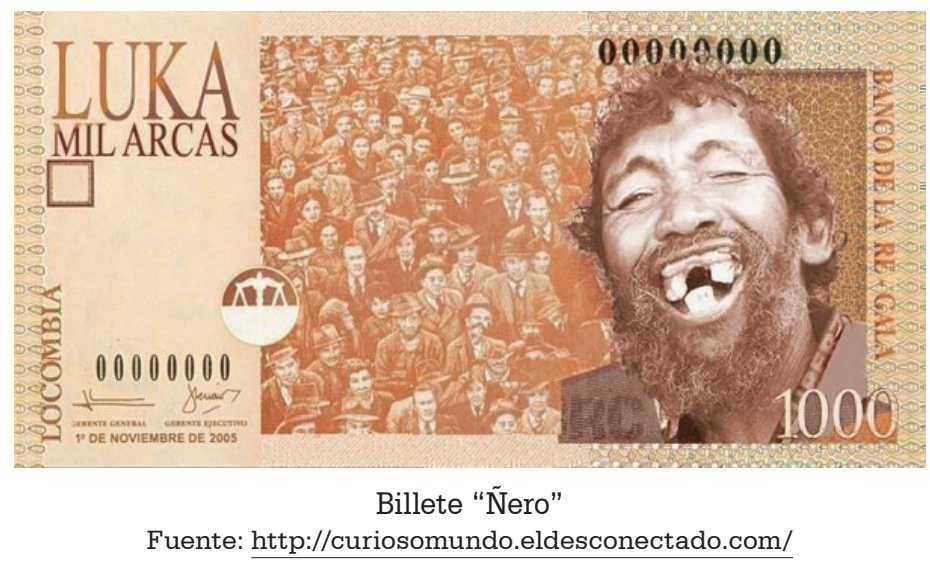

En este billete se interviene la figura de Gaitán y es reemplazada por la imagen de un mendigo en actitud burlesca. Esto puede significar la ironía del poder adquisitivo que tiene el billete o el poco peso que tiene el homenaje al caudillo con un billete de tan baja denominación, pero de gran circulación. 


\section{Billete con imagen del Guasón}

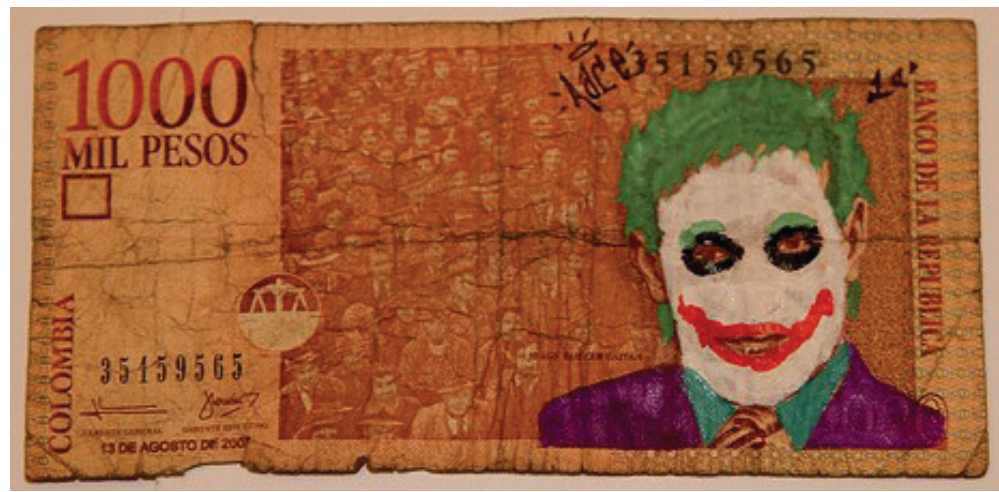

Billete "Guasón"

Fuente: https://www.flickr.com/photos/mundo-no-real

En este billete se interviene la figura de Gaitán y es sustituida por la imagen de un personaje de los cómics, el Guasón, personaje antagónico del héroe de acción "Batman". De manera sarcástica, al paladín de la justicia y los derechos como ha sido magnificado Gaitán se le antepone el antihéroe que defiende el terror y la muerte en los mencionados cómics.

\section{Billete con imagen de Ronald MacDonald}

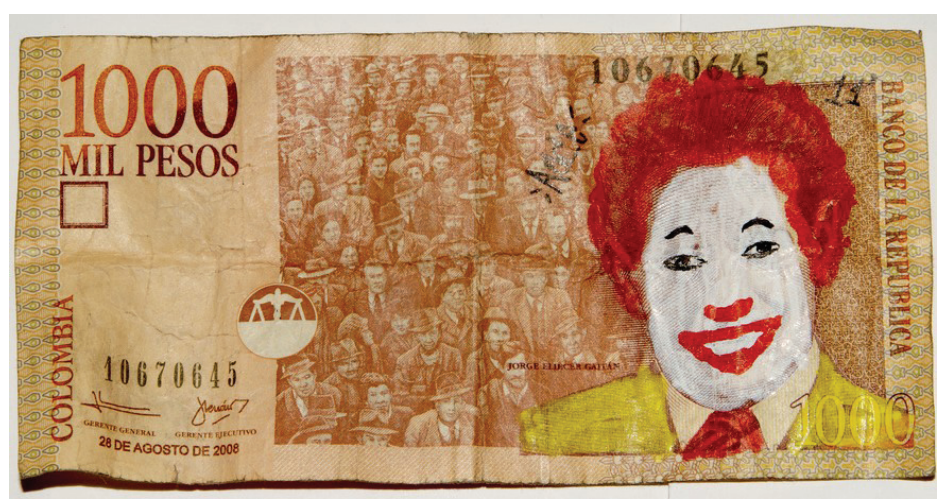

Billete "Ronald MacDonald"

Fuente: https://www.flickr.com/photos/mundo-no-real

En este billete se interviene la figura de Gaitán y es sustituida por la imagen de Ronald MacDonald, figura insigne de la multinacional de comidas rápidas MacDonald. Es significativo que se suplante a quien defendió postulados socialistas como fue Gaitán, con uno de los iconos del capitalismo mundial como es la imagen de payaso Ronald de la reconocida marca de hamburguesas. 
Moneda. Como se aprecia a continuación, la moneda conmemorativa al líder liberal data de 1965. En ella, se destaca su figura en alto relieve con una apariencia seria y serena, con una mirada fija hacia adelante, lo que da cuenta de un homenaje que convocaba a una especie de imperturbabilidad y apaciguamiento de sus seguidores después de dos décadas de su asesinato

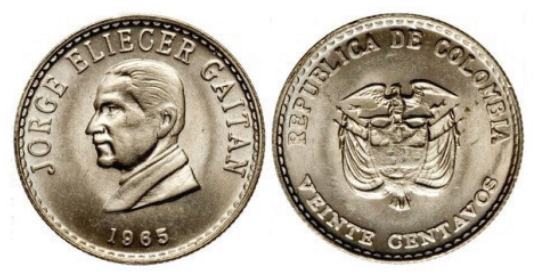

Moneda de 1965

Fuente: https://fr.numista.com/catalogue/pieces7540.html

Estampillas. Dos estampillas, que se ilustran a continuación, han circulado por el mundo recordando la memoria del Tribuno del Pueblo. La primera, de 1959, ilustra una estampa de perfil de Jorge Eliécer Gaitán destacando las fechas de su nacimiento y de su muerte. Su cara sobresale a hojas de laurel, para elogiar su grandeza como héroe o prohombre de Colombia. La segunda, de 1998, reproduce en color, la postura que definía el grado de vehemencia que asumía el líder cuando se dirigía a las masas. El color rojo de fondo busca recordar su filiación política con el Partido Liberal, sumado al eslogan que se repite siempre que se le menciona: "yo no soy un hombre, soy un pueblo", que, dicho sea de paso, electoralmente en muchas ocasiones ha sido utilizado por el partido liberal.

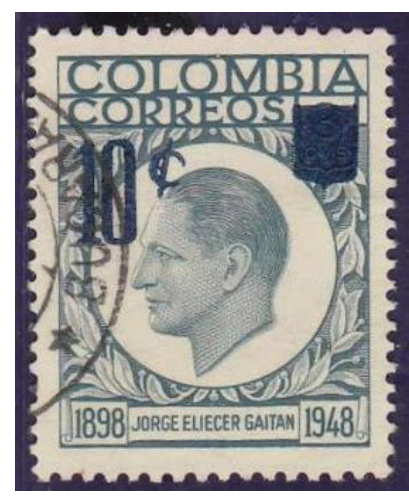

1958

Fuente: http://www.afitecol.com/

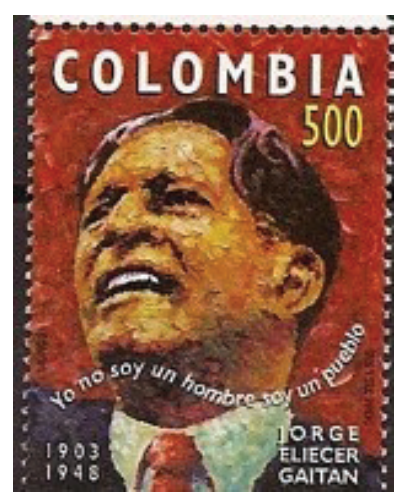

1998

Fuente: http://www.afitecol.com/ 


\section{Museo y lugares de memoria}

Los museos son dispositivos de memoria ${ }^{3}$ que agrupan objetos que representan épocas pasadas y visibilizan diversos tipos de identidades ${ }^{4}$, evocan recuerdos, remenearon acontecimientos e impregnan el presente con la añoranza del pasado. Se pueden concebir como "lugares rescatados de una memoria que ya no habitamos, mitad oficial e institucional, mitad afectiva y sentimental, lugares de unanimidad que ya no expresan convicción militante ni participación apasionada, pero donde todavía palpita algo de una vida simbólica" (Nora, 2009, p. 32).

Los lugares de memoria pertenecen a dos reinos; esto es lo que hace su interés, pero también su complejidad: simples y ambiguos, naturales y artificiales, inmediatamente ofrecidos a la experiencia más sensible y al mismo tiempo relevando la elaboración más abstracta. Son lugares, en efecto, en los tres sentidos de la palabra, material, simbólico y funcional, pero, simultáneamente, a grados solamente diversos (Nora, 2009, p. 32).

Esta última afirmación es de gran valor para nuestro análisis. En los museos como lugares de memoria convergen estos tres sentidos que sugiere Nora: material, simbólico y funcional. Material, en tanto recrean objetos del pasado para ser recordados en el presente; simbólico, porque conservan representaciones de una realidad pasada e invitan a salvaguardar imágenes y objetos ritualizados por su valor afectivo y simbólico; funcional, porque cumplen la tarea de mantener viva la memoria viva de acontecimientos pasados. La casa Mueso en honor a Jorge Eliécer Gaitán no escapa a esta dinámica:

Casa museo. La casa museo está ubicada en el barrio Santa Teresita al nororiente de la ciudad de Bogotá, lugar que representa una especie de santuario a la vida y trayectoria del líder.

3 Para Gonzalo Sánchez, la memoria colectiva o memoria social "define el marco de nuestras acciones, es aprendida, heredada y transmitida a través de innumerables mecanismos que le imprimen un sello a nuestro devenir, a tal punto que nuestra memoria termina siendo la representación de nosotros mismos ante los demás. Esto nos permite, en consecuencia, afirmar un primer gran postulado: La memoria es una forma esencial de construcción de las identidades colectivas. (Sánchez, 2000, p. 21).

4 Estas identidades sugieren a su vez la diversidad de la memoria social, pues "los diferentes grupos (sociales, nacionales, de género,) construyen de manera diferente sus memorias, sus temporalidades, sus legitimaciones, y a partir de estas le dan también su sentido propio al pasado en función del presente y definen sus aspiraciones identificatorias y futuras. Por ello también, más que generadora de consensos narrativos, míticos o visuales, la memoria es un terreno de disputa, de desestructuración y precomposición de las relaciones de poder. Evocar y silenciar son actos de poder (Sánchez, 2000, p. 21). 


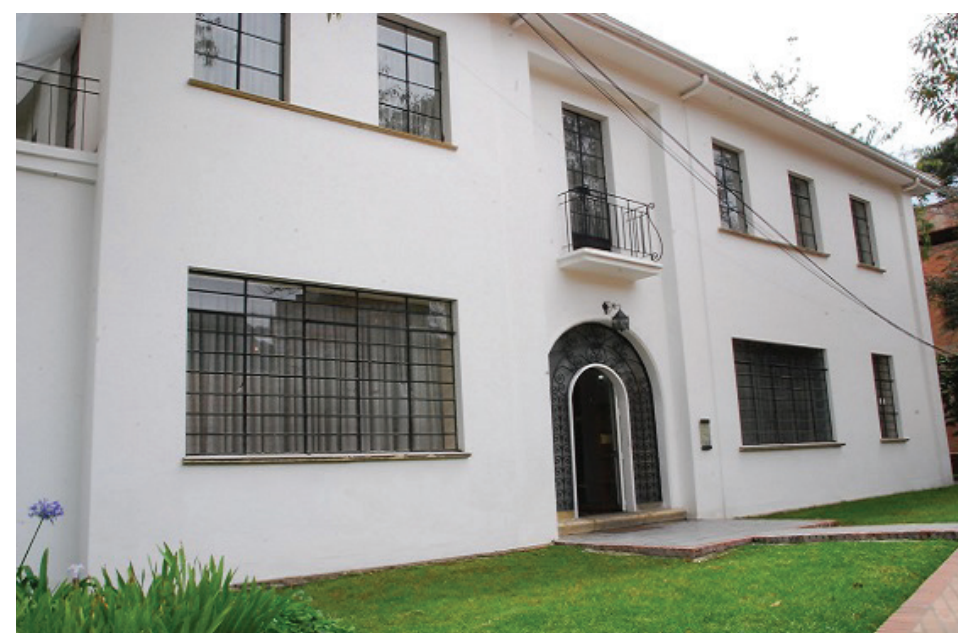

Casa Museo Jorge Eliécer Gaitán

Fuente: http://www.bogota.gov.co/en/node/13121

En la casa se conservan elementos como:

- Escritorio y objetos personales

- Un busto conmemorativo a su figura

- Fotografías familiares

- $\quad$ El traje utilizado el 9 de abril de 1948

- El arma con el que fue asesinado

- La puerta del edificio Agustín Nieto, que recuerda su oficina de abogado

- La tumba del dirigente político, que se puede apreciar a continuación:

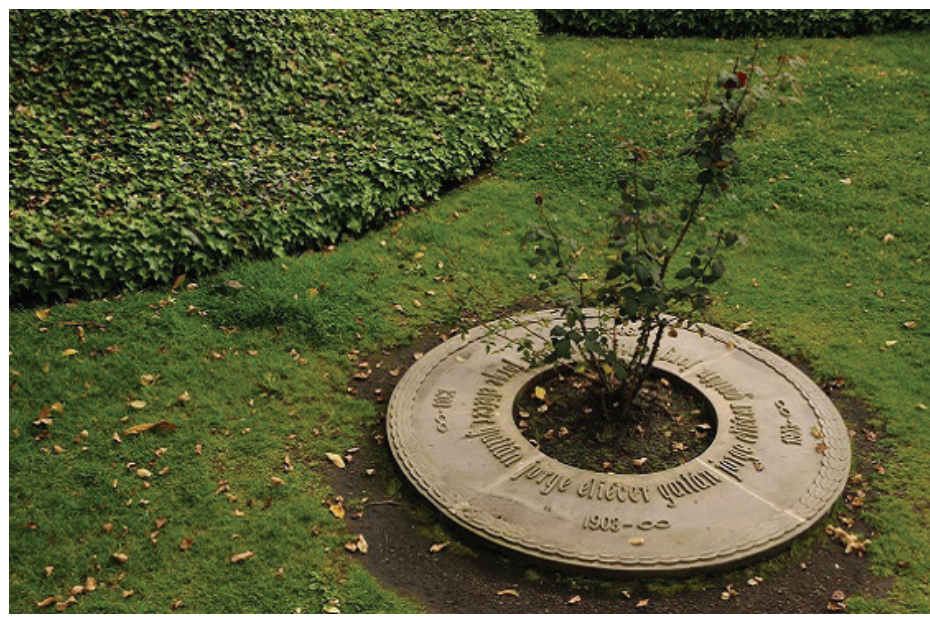

Lápida Jorge Eliécer Gaitán

Fuente: http://www.bogota.gov.co/en/node/13121 
En la lápida se puede observar el nombre del inmolado líder, y su fecha de nacimiento; se reemplaza la fecha de su muerte con el símbolo del infinito para dar cuenta de la inmortalidad de sus ideas y su pensamiento y perpetuar la grandeza del mito político.

Además de la casa museo se ubican otros lugares de memoria que buscan mantener viva la imagen de Gaitán. Un ejemplo de ello es la cantidad de colegios, escuelas e instituciones educativas que llevan su nombre y, en ocasiones, en el escudo de las mismas estampan la imagen del caudillo. Miremos los municipios colombianos y los departamentos donde se registra este tipo de lugares-homenaje:

Cuadro No. 2. Instituciones educativas con el nombre de Jorge Eliécer Gaitán en Colombia

\begin{tabular}{|c|c|}
\hline Departamento & Municipio \\
\hline \multirow{5}{*}{ Antioquia } & Bello \\
\hline & El Carmen de Viboral \\
\hline & Medellín \\
\hline & Nechí \\
\hline & Salgar \\
\hline Atlántico & Soledad \\
\hline \multirow{2}{*}{ Bolívar } & Barranco de Loba \\
\hline & Cartagena \\
\hline \multirow{2}{*}{ Boyacá } & Maripi \\
\hline & Tota \\
\hline \multirow{2}{*}{ Caquetá } & Florencia \\
\hline & Puerto Rico \\
\hline \multirow{5}{*}{ Casanare } & Morichal \\
\hline & Sabanalarga \\
\hline & Aguazul \\
\hline & La Salina \\
\hline & Yopal \\
\hline Cauca & Guachene \\
\hline \multirow{2}{*}{ Cesar } & González \\
\hline & Valledupar \\
\hline Córdoba & Montería \\
\hline \multirow{2}{*}{ Cundinamarca } & Soacha \\
\hline & Bogotá \\
\hline Guajira & Maicao \\
\hline
\end{tabular}


Carlos A. Flórez López

\begin{tabular}{|c|c|}
\hline Departamento & Municipio \\
\hline Huila & Gigante \\
\hline Magdalena & Santa Marta \\
\hline \multirow{3}{*}{ Meta } & Mapiripán \\
\hline & Puerto Gaitán \\
\hline & Villavicencio \\
\hline \multirow{4}{*}{ Nariño } & Cumbal \\
\hline & El Peñol \\
\hline & Pasto \\
\hline & Policarpa \\
\hline \multirow{2}{*}{ Putumayo } & Leguízamo \\
\hline & Orito \\
\hline Quindío & Armenia \\
\hline Risaralda & Pereira \\
\hline \multirow{3}{*}{ Santander } & Bucaramanga \\
\hline & Lebrija \\
\hline & Floridablanca \\
\hline \multirow{4}{*}{ Tolima } & Cajamarca \\
\hline & Flandes \\
\hline & Ibagué \\
\hline & Líbano \\
\hline \multirow{4}{*}{ Valle del Cauca } & Buenaventura \\
\hline & Sevilla \\
\hline & Palmira \\
\hline & Restrepo \\
\hline Vichada & Puerto Carreño \\
\hline
\end{tabular}

Fuente: elaboración propia

Los lugares-homenaje no se agotan a nombres de colegios, que por cierto están a lo largo y ancho del territorio colombiano. Por ejemplo, se encuentran referencias desde el nombre de un municipio hasta nombres de barrios, parques, plazas, hospitales, entre otros lugares. A continuación, se relaciona una lista con los mismos, en los respectivos municipios y departamentos: 
Cuadro No. 3. Otros lugares de memoria

\begin{tabular}{|c|c|c|}
\hline Lugares & Departamento & Municipio \\
\hline Municipio & Meta & Puerto Gaitán \\
\hline \multirow{15}{*}{ Barrios } & Amazonas & Leticia \\
\hline & Antioquia & Medellín \\
\hline & Bolívar & Cartagena \\
\hline & Boyacá & Tunja \\
\hline & Cauca & Popayán \\
\hline & \multirow{2}{*}{ Cundinamarca } & Bogotá \\
\hline & & Fusagasugá \\
\hline & Huila & Neiva \\
\hline & Norte de Santander & Cúcuta \\
\hline & Santander & Bucaramanga \\
\hline & Sucre & Sincelejo \\
\hline & Tolima & Ibagué \\
\hline & \multirow{3}{*}{ Valle del Cauca } & Buga \\
\hline & & Cali \\
\hline & & Tuluá \\
\hline \multirow{2}{*}{ Avenidas } & Antioquia & Medellín: Avenida Oriental \\
\hline & Cundinamarca & Bogotá: calle 26 \\
\hline \multirow{2}{*}{ Centros de Salud } & Santander & Bucaramanga \\
\hline & Tolima & Ibagué \\
\hline Hospitales & Cundinamarca & Bogotá \\
\hline Teatro & Cundinamarca & Bogotá \\
\hline Auditorio & Norte de Santander & Universidad de Pamplona \\
\hline Consultorio Jurídico & Cauca & Universidad del Cauca \\
\hline Cátedra Universitaria & Cundinamarca & $\begin{array}{l}\text { Universidad Nacional de Colombia. Sede } \\
\text { Bogotá }\end{array}$ \\
\hline Concurso de oratoria & Atlántico & Universidad Libre Seccional Barranquilla \\
\hline Lugares & Departamento & Municipio \\
\hline \multirow{5}{*}{ Parques } & Antioquia & Medellín \\
\hline & \multirow{2}{*}{ Boyacá } & Paz del Río \\
\hline & & Puerto Boyacá \\
\hline & Caldas & La Dorada \\
\hline & Cundinamarca & Bogotá \\
\hline
\end{tabular}




\begin{tabular}{|l|l|l|}
\hline \multicolumn{1}{|c|}{ Lugares } & \multicolumn{1}{|c|}{ Departamento } & \multicolumn{1}{c|}{ Municipio } \\
\hline & Risaralda & Pereira \\
\hline & Valle del Cauca & Cartago \\
\hline Estadio & Antioquia & Puerto Berrío \\
\hline Palacio Municipal & Antioquia & Caldas \\
\hline Vereda & Huila & Campoalegre \\
\hline Casa de la cultura & Meta & Villavicencio \\
\hline Centro cultural & Meta & Puerto López \\
\hline $\begin{array}{l}\text { Biblioteca pública } \\
\text { municipal }\end{array}$ & Cauca & Santander de Quilichao \\
\hline
\end{tabular}

Fuente: elaboración propia

Los homenajes van más allá de la toponimia de los lugares. Los militantes fieles al caudillo liberal fueron mucho más allá, y quienes tenían el apellido Gaitán decidieron colocarles a sus hijos Jorge Eliécer e incorporaron a su familia el recuerdo de su ídolo político, tal como lo sostiene Laverde:

En Colombia figuran 362 personas con ese nombre: Jorge Eliécer Gaitán. Sólo seis sobrellevan el calvario bautismal de su verdugo: Juan Roa. Son datos precisos de la Registraduría Nacional del Estado Civil. Y aunque escurre menos originalidad, naturalmente el nombre del efervescente liberal ha protagonizado más bautizos en los últimos 60 años que el del asesino de marras. Y llenó el país de tocayos que perpetúan su nostalgia. En especial en esta época (El Espectador, 9 de abril de 2013).

\section{Monumentos}

Los monumentos también son considerados como lugares de memoria, donde se recrea la imagen de un personaje, un símbolo o una conmemoración. Por ello, "partimos de la idea de que los monumentos constituyen uno de los tantos artefactos u objetos creados para recordar o conmemorar algo" (Vaca, 2013, p. 114).

En Colombia, la mayoría de parques que tienen el nombre de Jorge Eliécer Gaitán poseen un monumento en forma de estatua o busto conmemorativo. En la mayoría de los monumentos de cuerpo entero se representa la imagen icónica del líder liberal que ha circulado en folletos, afiches, libros o periódicos. Los artistas han recurrido a elaborar estatuas en actitud combativa, con su mano derecha cerrada en puño, acompañado de manera explícita o tácita el lema "A la carga". Esta idea de monumento ha sido reproducida en varios lugares del País ${ }^{5}$. Analicemos algunos ejemplos:

5 Esta misma idea de monumento se ha reproducido en otros sitios como el Parque Gaitán de Medellín, cuya estatua fue realizada por Octavio Montoya Estrada, el Parque Gaitán de Cúcuta, cuya escultura fue realizada 
Cuadro No. 4. Estatuas de Jorge Eliécer Gaitán

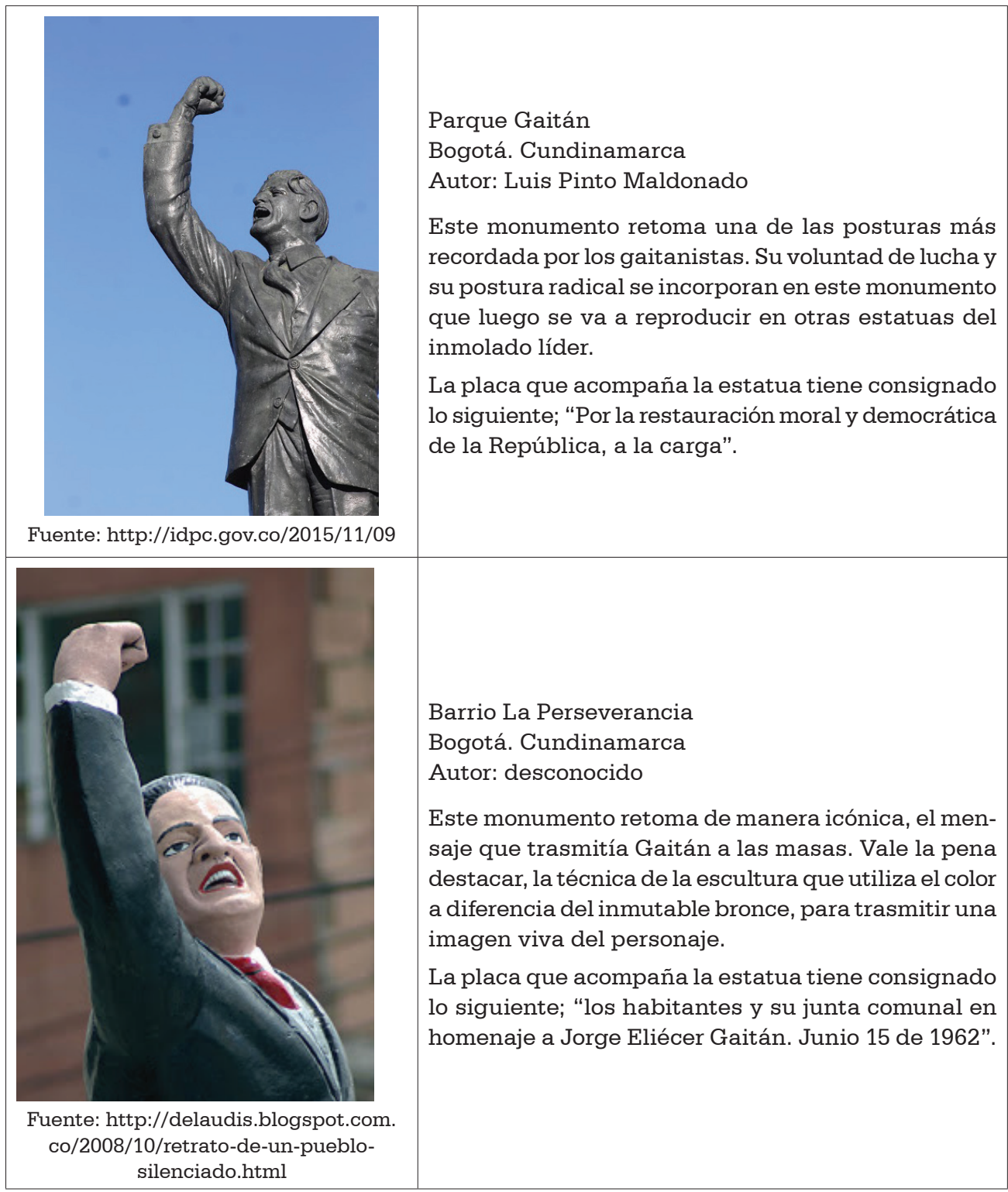

Sumados a las estatuas, otros monumentos se han realizado en homenaje a Jorge Eliécer Gaitán, convertidos en otros lugares de memoria, pero, esta vez, analizaremos los bustos que también abundan en varios lugares del País ${ }^{6 .}$

por Guillermo Ortiz Ramírez, el Parque Gaitán de La Dorada, de autor desconocido o el Parque Gaitán de Girardot restaurado por Alejandro Hernández Pinto.

6 En otros parques se encuentran otros bustos de Gaitán. Por ejemplo, en el parque Gaitán de Tuluá se encuentra 
Tomemos tres ejemplos;

\section{Cuadro No. 5. Bustos de Jorge Eliécer Gaitán}

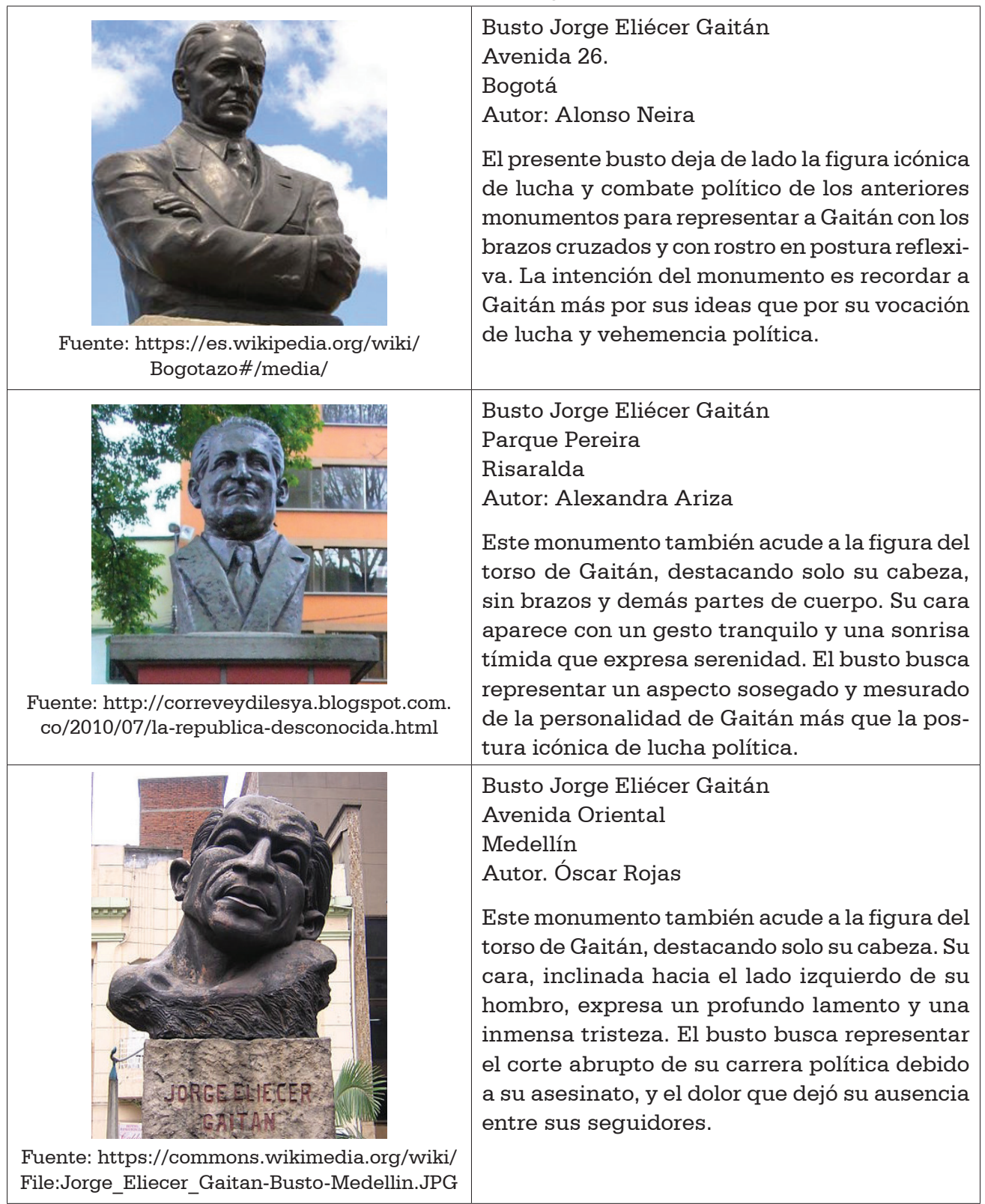

Fuente: elaboración propia

un busto realizado por Ernesto Buzzi, en el Congreso de Colombia se encuentra otro busto elaborado por Bernardo Vieco, en el parque Gaitán de Zarzal se encuentra otro busto de autor desconocido. 
Ahora bien, las representaciones de la muerte de Gaitán no se agotan en los lugares de memoria o monumentos adecuados para tal fin, o los homenajes llevados a cabo en monedas, billetes y estampillas. Caricaturistas ${ }^{7}$ también se han sumado a recordar su memoria con la imagen icónica de Gaitán en la tribuna dirigiéndose en forma vehemente a las masas. Miremos algunos ejemplos ${ }^{8}$ :

\section{Cuadro $N^{\circ}$. 6. Caricaturas de Jorge Eliécer Gaitán}

Fuente: http://restrepho.wixsite.com/ $\begin{aligned} & \text { Caricatura: Jorge Eliécer Gaitán } \\ & \text { Autor. Jorge Alberto Restrepo } \\ & \text { En esta viñeta se ilustra el líder liberal en } \\ & \text { una especie de atrio, dirigiéndose al pa- } \\ & \text { recer de manera vehemente a las masas. } \\ & \text { De su boca abierta sale su mano derecha } \\ & \text { cerrada en actitud de lucha. El caricatu- } \\ & \text { rista quiere destacar el icono de lucha } \\ & \text { social que trasmitía Gaitán y la fuerza que } \\ & \text { rezumaba en sus discursos. }\end{aligned}$

7 Las caricaturas son una fuente clave para percibir la imagen valorativa de una época, un acontecimiento o la percepción de personajes. Como lo sugiere Peter Burke: "pueden ser utilizadas con cierta garantía para reconstruir unas actitudes o mentalidades políticas perdidas" (Burke, 2001, pág. 100); también Acevedo sostiene que "las caricaturas presentan la realidad política, como expresión que es de un ambiente o clima de enfrentamiento, como forma de mirar los hechos de la política, como vehículo que da cuenta de los imaginarios políticos, que divulga imágenes sintetizadas y que, por tanto, contribuye a la producción de identidades y al desarrollo de corrientes de opinión pública (Acevedo, 2003, pág. 158); finalmente, "la caricatura se convierte en una fuente muy particular, que se distingue de las demás. Como producto de la acción humana, es una creación con fuerza propia (Flórez, 2015, p. 118).

8 Otros caricaturistas han sido recurrentes en esta representación de Gaitán. Véase la caricatura de Gaitán de Walter Toscano: http://wtoscano.blogspot.com.co, o la caricatura de Gaitán de Stella Peralta en stellaperaltacaricatura.blogspot.com.co. 


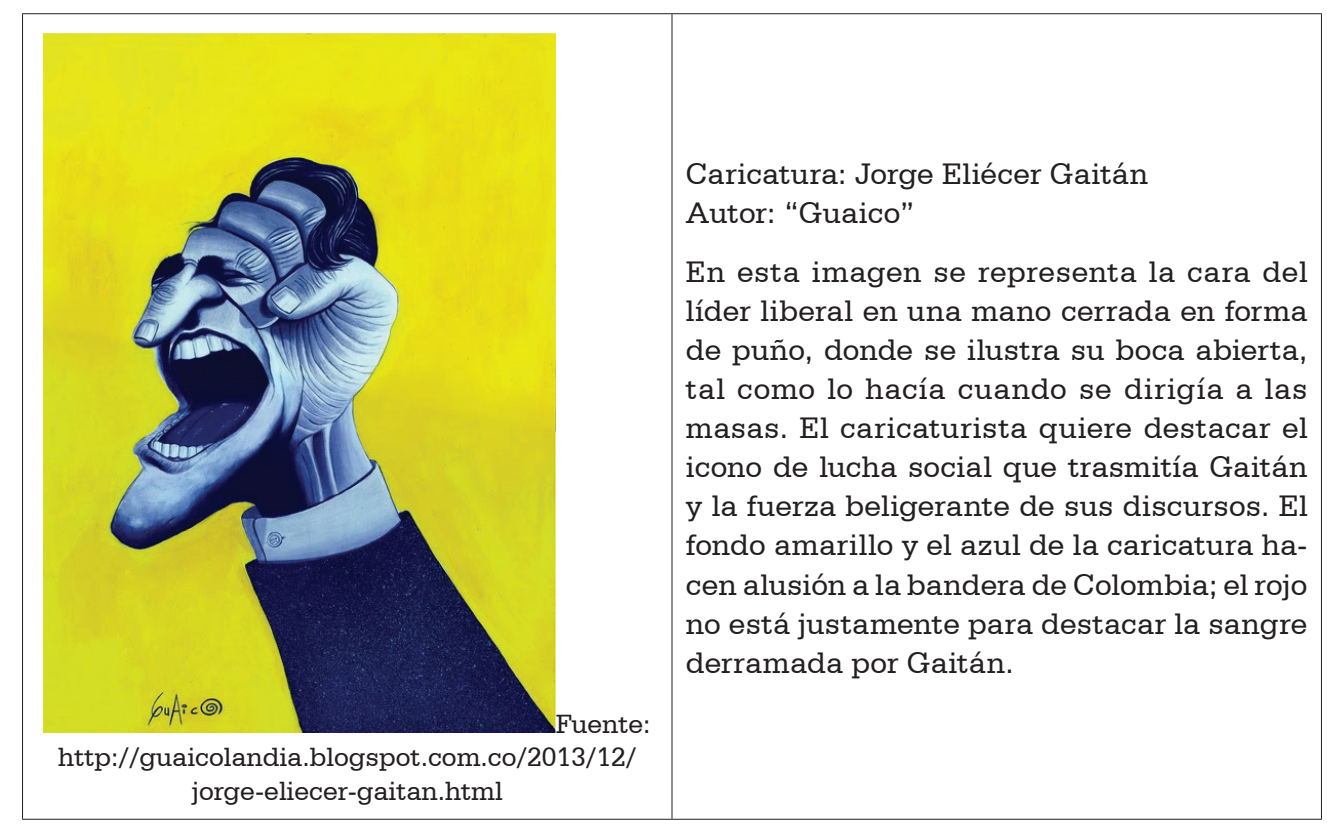

\section{Conclusión}

El mito político de Gaitán está presente a lo largo y ancho de la geografía nacional. Instituciones educativas, parques, hospitales, estadios, murales, veredas y hasta nombres de personas recuerdan al caudillo liberal y trasmiten lugares de memoria que enaltecen sus ideas, posturas y, en especial, su forma de hacer política.

La monumentaria que se encuentra en parques y calles se divide en dos categorías: en primer lugar, el monumento completo de pies a cabeza del líder, -con su mano alzada, con puño cerrado, tal como lo hacía en los discursos en la plaza pública convocando al pueblo a seguir sus ideas de manera beligerante y combativa-, trasmite la idea del caudillo que no muere y que está presente para recordar las razones que motivaron su lucha y las consecuencias de su asesinato. En segundo lugar, los bustos que solo destacan medio cuerpo, sobresaliendo su torso y cabeza, algunos con las manos cruzadas y otros solo la cabeza, dan cuenta de la intencionalidad de preservar sus ideas y su presencia, más que la combatividad y beligerancia a la que hacen alusión las demás estatuas. Las caricaturas señaladas evocan la figura del líder combativo, pues, su mano, su cuerpo y su cabeza se funden en una sola idea: su lucha por las reivindicaciones sociales y las masas que representaba al proclamarse no como un "hombre" sino como la encarnación de "un pueblo".

En definitiva, los lugares de memoria destinados a conmemorar el legado 
político de Gaitán destacan al mártir, al ídolo de multitudes, al héroe caído que está presente en la memoria colectiva de quienes defienden su legado y de quienes son sus detractores. El debate está abierto. ¿Son lugares para recordar per se, para hacer catarsis individual o colectiva, para reparar simbólicamente al pasado, para no repetir acontecimientos trágicos o para calmar la sed de memoria colectiva? Sin duda, hacen falta mayores trabajos investigativos para abordar las respuestas a estos interrogantes.

\section{Referencias bibliográficas}

Acevedo, D. (2003). La caricatura editorial como fuente para la investigación de la historia de los imaginarios políticos: reflexiones Metodológicas. Revista Historia y sociedad, N. ${ }^{\circ}$, marzo, pp. 151-174.

Burke, P. (2001). Visto y no visto. El uso de la imagen como documento histórico. Barcelona: Editorial Crítica.

Flórez, C. (2015). Imaginarios políticos de la participación ciudadana en la Asamblea nacional constituyente de Colombia de 1991. Medellín: Universidad de Medellín- UniRemington.

(Le Goff, (1991). El orden de la memoria. El tiempo como imaginario, Barcelona: Ediciones Paidós.

Nora, P. (2009). En les Lieux de Mémoire. Santiago de Chile: LOM ediciones- Trilce.

Sánchez, G. (2000). Memoria, museo y nación, Bogotá: Ministerio de Cultura.

Tachar, M. (2009). La presencia de una ausencia: Jorge Eliécer Gaitán y las desventuras del populismo en Colombia. Araucaria. Revista Iberoamericana de Filosofía, Política y Humanidades, N. ${ }^{\circ} 22$. Segundo semestre de 2009, pp. 251-262.

Vaca, R. (2013). La monumentaria urbana en el escenario de las luchas políticas locales. Revista digital de la Escuela de Historia - Unir / año 5-N. ${ }^{\circ}$ 9, pp. 11-136. 